\title{
Cost estimation of utility strikes: towards proactive management of street works
}

Lewis O. Makana MEng (Hons), PhD, GMICE

Senior ATU Coordinating Research Fellow, Department of Civil

Engineering, School of Engineering, University of Birmingham, Birmingham, UK (corresponding author: I.makana@bham.ac.uk) (Orcid:0000-0003-2311-6797)

Nicole Metje Dipl. Eng, PhD, MASCE, MCInstCES, FHEA Professor of Infrastructure Monitoring, Department of Civil Engineering, School of Engineering, University of Birmingham, Birmingham, UK; National Buried Infrastructure Facility, UK Collaboratorium for Research in Infrastructure and Cities, School of Engineering, University of Birmingham, Birmingham, UK (Orcid:0000-0002-6741-8183)
Ian Jefferson BEng (Hons), DIS, PhD, FGS

Professor of Geotechnical Engineering, Department of Civil Engineering, School of Engineering, University of Birmingham, Birmingham, UK; National Buried Infrastructure Facility, UK Collaboratorium for Research in Infrastructure and Cities, School of Engineering, University of Birmingham, Birmingham, UK (Orcid:0000-0001-6437-101X)

Margaret Sackey CEng, MICE, CMIOSH, FMAPS, MIIAI, MCMI Senior CDM Co-ordinator and H\&S Advisor, Health and Safety Executive, Transport for London, London, UK

Chris D. F. Rogers Eur Ing, BSC, PhD, CEng, MICE, MIHT Professor of Geotechnical Engineering, Department of Civil Engineering, School of Engineering, University of Birmingham, Birmingham, UK; National Buried Infrastructure Facility, UK Collaboratorium for Research in Infrastructure and Cities, School of Engineering, University of Birmingham, Birmingham, UK (Orcid:0000-0002-1693-1999)

The true (full) cost of a utility strike incident is rarely known. Generally, only the direct costs are used to measure the impact of utility strikes; the wider indirect and social costs are rarely quantified in monetary terms. Moreover, no established methodology exists to address this gap in knowledge, while access to fully documented records often presents the greatest challenge. This paper presents research that for the first time has been given access to 16 fully detailed utility strike case studies in UK urban areas. The research has identified and assessed the impacts of these utility strikes and provided an objective estimation of their associated (total) costs. These costs consist of those paid directly by the utility owner (direct costs), those borne by third parties in the contractual agreement (indirect costs) and those borne by other parties not engaged in the contractual agreement (social costs). Although the richness lies in the detailed case studies, the aggregated findings from all 16 utility strike case studies indicate that the total cost ratio - the ratio of indirect and social costs to the direct cost of repair - is 29:1. Thus there is a very substantial impact, which to date has been largely neglected.

\section{Notation \\ $j \quad$ day within a $24 \mathrm{~h}$ traffic flow segment \\ $R^{2} \quad$ coefficient of determination \\ $s \quad$ traffic segment within $24 \mathrm{~h}$ traffic flow cycle}

\section{Introduction}

A wide range of equipment and operational procedures are utilised in street works to repair, replace and maintain buried infrastructure, including pipes and cables, chosen to satisfy project costs first and maximise profits, in addition to meeting operational time constraints (Rogers et al., 2012). More often than not, access to buried pipes and cables is achieved through excavation from the surface using open trenches (ASCE, 2002; Metje et al., 2007), and as such a utility strike is a constant risk due to the techniques employed - for example, use of mechanical excavators. A utility strike occurs when any element of the utility network infrastructure is hit, leading to damage, during excavation (Usag, 2016), and can be caused by a whole host of reasons, as illustrated in Figure 1 .

A review of the literature (Hunt et al., 2014; Jung and Sinha, 2007; McMahon et al., 2005; Moran et al., 2017; Ormsby, 2009; Woodroffe and Ariaratnam, 2008) shows that a variety of terms have been used to define the different costs related to buried asset infrastructure, and rather confusingly, several studies have used identical terms to define different types of costs. For clarity, it is therefore necessary to define clearly the terminology prior to examining the costs themselves. For the purposes of this study, the costs of buried asset infrastructure will be cost estimated under the following three categories: direct costs (DCs), indirect costs (ICs) and social costs (SCs).

When a utility strike incident happens, the utility owner often incurs the direct construction costs of the strike incident - that is, planning, supervision, material, design and labour costs (Goodrum et al., 2008; Metje et al., 2015). However, there are ICs, additional costs associated with the contracts incurred by the utility company and third parties due to, for example, loss of business income (Bernold, 2003; Gilchrist and Allouche, 2005). SCs are those which are a result of the street works, but which are borne by society and the environment instead of the utility companies and include costs to other businesses, increased levels of air pollution as well as noise, damage to the environment and traffic delays experienced by road users due to the additional works, which are paid for by society (McMahon et al., 2005). When combined, these DCs, ICs and SCs are the 'true costs' linked to utility strike incidents.

Moreover, when taking account of works undertaken on or beneath the highway, the division should be made between street 


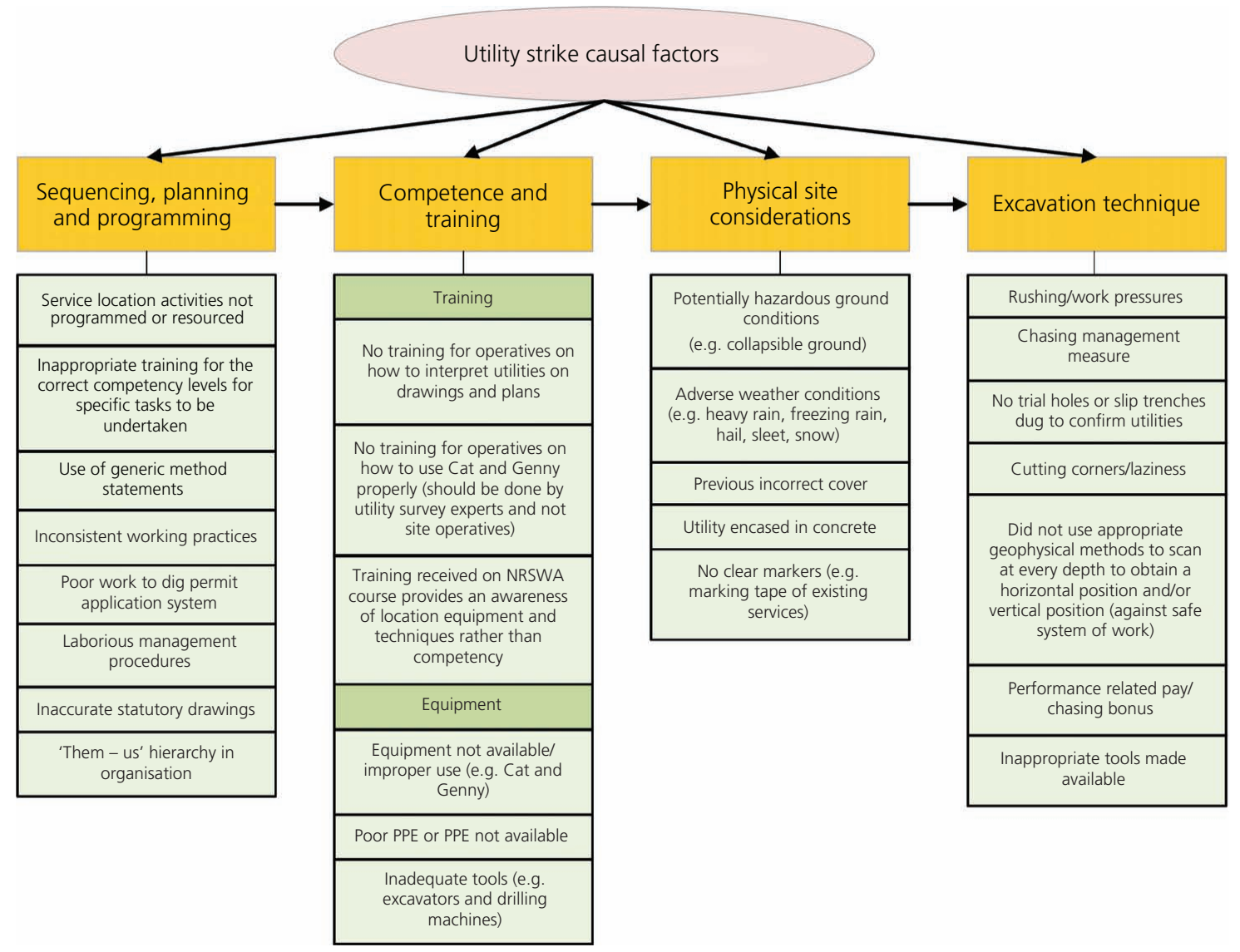

Figure 1. The multiple causal factors of utility strikes in street works. NRSWA, New Roads and Street Works Act; PPE, personal protective equipment

works (which are undertaken by statutory undertakers, e.g. water companies) and highway works (which are maintenance works undertaken by the highway authorities). Predictably, costs will arise with all such works, but the focus of this study is the costs connected with buried asset infrastructure and so will of necessity give attention to street works. In point of fact, most of the literature on the disruptive consequences of road works tends to concentrate on the effects of street works (Hunt et al., 2014; Jung and Sinha, 2007; Matthews et al., 2015; McMahon et al., 2005; Woodroffe and Ariaratnam, 2008).

More than 4 million holes are excavated in UK roads each year (McMahon et al., 2005), with approximately 60000 utility strikes occurring annually in the UK alone (ICE, 2017), contrasted with 500000 in the USA (Talmaki and Kamat, 2012), and with increasing debates over traffic congestion and its impacts on public and private transport service disruption (Litman, 2017), local authority austerity and the need to maintain services (Pike et al., 2017) and the imperatives of urban sustainability and resilience (Hunt et al., 2016; Makana et al., 2016a), research is needed whose implications, and direction towards far more effective street works, are potentially transformative (Clarke et al., 2017; Hojjati et al., 2017; Makana et al., 2017; Rogers et al., 2017).
The study herein presented is therefore the first attempt on both the national and international levels to put forward explicitly a methodology for cost estimating through case studies the full economic impact of utility strikes - that is, the sum of DCs, ICs (if any) and SCs (if any) that are a by-product of a utility strike incident. This paper presents research that for the first time has been given access to 16 fully detailed utility strike case studies in a UK urban area. The research has identified and assessed the impacts of these utility strikes and provided an estimation of their associated costs. Perhaps more important still is the fact that the evidence base presented in this paper, until now, has been nonexistent, with this paper filling the long-awaited evidence gap that permits asset owners and other urban professionals to demand changes towards safer and more sustainable, resilient and liveable city practices (Rogers, 2018).

\section{Literature review: cost estimation of utility strikes}

The debate in the infrastructure sector around the costs that arise through utility strikes has been ongoing for a long time (Sanghvi, 1982), with little or no evidence to substantiate any estimates conclusively until recently (Metje et al., 2015). Construction industry contracts often do not account for the wider economic 
losses resulting from utility strikes, which are experienced by parties not involved in the contractual agreement (Broome and Perry, 2002). This typically occurs because contractors and utility owners seldom have to substantiate their selection of construction methods and procedural routines based on any cost estimation methodology that takes into account the costs borne by society (Gilchrist and Allouche, 2005). ICs and SCs resulting from a utility strike incident are generally not recorded, and the current data collection and information management systems used in industry do not capture the information that can estimate the total costs of utility strikes in a systematic fashion (CGA, 2015; Metje et al., 2015; Usag, 2016), hence the key impact of this research. In infrastructure planning literature, there are currently attempts to explicitly estimate the cost of the wider impact (DCs, ICs and SCs combined) of utility strikes and straddle the interface between the utilities project, the economic system and the socio-ecological system in which the strike incident has occurred.

Within these limitations, Metje et al. (2015) presented the first attempt to compile a compendium of utility strike costs (3348 provided by four contractors, two clients and two utility companies across the UK), centred specifically on the DCs incurred. However, even here the ICs and SCs of each strike incident were not taken into account and the need for an approach allowing a wider range of costs was highlighted. Goodrum et al. (2008) provided a similar attempt to estimate the impact of utility conflicts (disruptions when utility installations are encountered unexpectedly during construction) during construction projects through statistical analysis of surveys from 45 different US states, with the study focusing on detailing their frequency and severity, in addition to four separate case studies, nested in the overall study, in which utility strike incidents (or hits) were experienced, and the resulting direct and ICs they brought about provided by the utility company in question. However, the cost estimation methodology behind each of these strike costs was not explained, as these costs were provided by individual case study companies and no SCs were accounted for. Moreover, several studies in the USA have attempted to cost estimate (based on a cost-benefit analysis) potential utility management savings through a number of approaches - for example, using subsurface utility engineering - but no methodology for explicitly estimating the cost of the wider impact of utility strikes was presented in any way (Bell et al., 2014; Bernold, 2003; Goodrum et al., 2006; Jung and Sinha, 2007; Kraus et al., 2012; Lew, 2000; Osman and El-Diraby, 2005; Sinha et al., 2007; Woodroffe and Ariaratnam, 2008). Other relevant studies have attempted to assess how to cost estimate utility strike incidents, but none have provided a methodology to do so or estimated the total cost of any incident cases (Brady et al., 2001; Çelik et al., 2017; CGA, 2015; Gilchrist and Allouche, 2005; Hojjati et al., 2018; Hunt et al., 2014; Matthews et al., 2015; McMahon et al., 2005; Moran et al., 2017; Najafi and Kim, 2004; Ormsby, 2009; Wang et al., 2008).

\section{Methodological approach}

The methodology used to estimate the cost of utility strikes is illustrated in Figure 2, and more details are provided by Makana et al. (2016b). Figure 2 shows the case study approach used that focuses on each case study individually and then draws crosscutting conclusions, using utility strike cost indicators detailed in Table 1 as the unit of analysis, drawing from the work of Yin (2013), who sets out the general principles to be observed in case study research design and methods. As a result, no clear rationale distinction is drawn in the present study between the commonly understood classic single-case study and multiple-case studies. The three different phases of the 'new approach' utility strike cost estimation methodology as shown in Figure 2 are summarised the

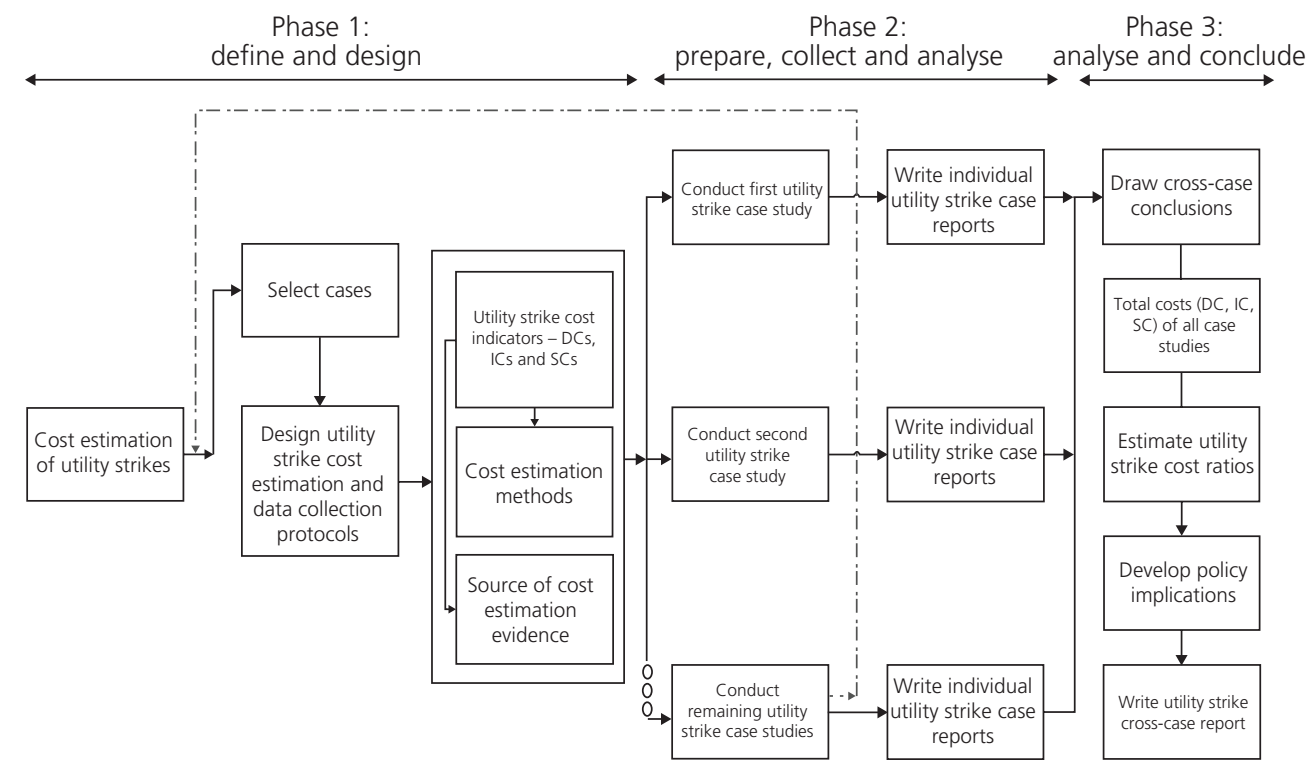

Figure 2. Utility strike new approach multiple-case study cost estimation methodology - adapted from Yin (2013) 
Table 1. Examples of utility strike cost indicators that could occur when a utility strike incident happens

\begin{tabular}{|c|c|c|c|}
\hline Cost category & Utility strike cost indicator & $\begin{array}{l}\text { Cost estimation, } \\
\text { possible methods }{ }^{a}\end{array}$ & $\begin{array}{l}\text { Cost estimation evidence, } \\
\text { possible sources }\end{array}$ \\
\hline \multirow[t]{7}{*}{$D C s^{c}$} & Administrative costs (DC1) & 1,2 & 1,3 \\
\hline & Planning and design (DC2) & 1,2 & $1,3,4$ \\
\hline & Diversion of existing utility services (DC3) & 3,5 & 1,4 \\
\hline & Supervision of construction works (DC4) & 3,5 & 3,4 \\
\hline & Traffic management (DC5) & 5 & 3,4 \\
\hline & Material and construction costs (DC6) & 3,5 & $1-3$ \\
\hline & Cost of repair (DC7) & 4 & $1-3$ \\
\hline \multirow[t]{9}{*}{$\mathrm{ICs}^{\mathrm{d}}$} & Increased insurance premiums (IC 1) & - & 1,2 \\
\hline & Regulatory fines (e.g. HSE) (IC2) & - & 1,2 \\
\hline & Damage to third-party apparatus (IC3) & 5 & 3,4 \\
\hline & Programme overrun (IC4) & 1,2 & 1,4 \\
\hline & Loss of business income (IC5) & 1,2 & 1,2 \\
\hline & Compensation payments (IC6) & 1,2 & $1-3$ \\
\hline & Insurance excess payments (IC7) & 5 & 1,2 \\
\hline & Damage to brand/image (IC8) & 1,2 & $1,3-6$ \\
\hline & Cost of restoring brand/image (IC9) & $2,3,8$ & $1,3,5,6$ \\
\hline \multirow[t]{6}{*}{$\mathrm{SCs} s^{\mathrm{e}}$} & Traffic delay costs (SC1) & 4 & 3,4 \\
\hline & Costs to local business (SC2) & $1-6$ & 2,3 \\
\hline & Costs to highway (transport) users (SC3) & $4,6,7$ & 2,3 \\
\hline & Environmental costs (SC4) & 2,8 & 2,3 \\
\hline & Costs to highway authority (SC5) & $4,6,7$ & $2-5$ \\
\hline & Costs to local community (SC6) & 6,8 & $2,5,6$ \\
\hline
\end{tabular}

apartially after Gilchrist and Allouche (2005) and Tsunokawa and Hoban (1997). Direct methods: 1, loss of productivity; 2, human capital; 3, replacement cost; 4, lane closure cost; 5, Spon's price book (AECOM, 2017) (or similar country equivalent). Indirect methods: 6 , hedonic pricing; 7 , user delay cost; 8 , contingent valuation technique

${ }^{b} 1$, company documents; 2 , archival records; 3 , open-ended interviews; 4 , site visits - direct and participant; 5 , structured interviews and surveys; 6 , focus interviews ${ }^{\mathrm{C} C o s t s}$ paid directly by contractors

${ }^{\mathrm{d} C o s t s}$ borne by third parties in the contractual agreement

${ }^{e}$ Costs borne by other parties not engaged in the contractual agreement

The numbers in the first column indicate the possible methods that can be used for cost estimation of the cost indicator; the numbers in the second column indicate possible sources of cost estimation evidence

HSE, health and safety executive

sections headed 'Phase 1: define and design', 'Phase 2: prepare, collect and analyse' and 'Phase 3: analyse and conclude'.

\section{Phase 1: define and design}

For the define and design phase, the selection of utility strike case studies is made and the focus in the selection process should be, if possible, the selection of individual projects which include a mix of utilities and a mix of projects ranging from simple to complex. A key criterion (where possible) for the selection of cases is still the use of interviews of key actors - for example, contractors thus providing important context as to why the utility strike incident happened and the conditions around the incident on the day. Moreover, interviews provide key information where a paper record of the utility strike incident is not available.

The next important step requires the definition of cost estimation measures for each utility strike case study. These measures are shown in the study utility strike cost indicators, drawn from Table 1, and have been grouped into DC, IC and SC indicators. A utility strike cost indicator is defined here as a 'measurable cost which in monetary terms can be quantified and is a consequence of one or more utility strike-related negative impacts on the environments surrounding a utilities project' and affords the opportunity for extensive analysis into a single case. A total of 22 representative cost indicators were carefully chosen from appropriate published engineering literature (Bernold, 2003; Goodrum et al., 2008; Jung and Sinha, 2007; Lew, 2000; McMahon et al., 2005; Metje et al., 2015; Najafi and Gokhale, 2005; Osman and El-Diraby, 2005). The following criteria were used to select cost indicators in this study.

- Relevance: There is a clear relationship between utility strike cost estimation and the indicator.

- Usefulness: The indicator will point to areas of improvement and helps capture information to facilitate moving utility strike avoidance strategies, priorities or programming forward.

- Feasibility: Cost estimation data for the indicator can be obtained with reasonable and affordable effort.

- Validity: To the extent possible, the indicator has been field tested and used in practice for cost estimation exercises previously.

- Distinctiveness: The indicator lacks redundancy and does not duplicate measures captured by other indicators.

Table 1 shows the relationship between the utility strike cost indicators, the cost estimation methods (direct and indirect) that could be used to estimate the strike cost indicator and the multiple sources of evidence that are available to establish a chain of evidence during data collection. The cost estimation methods presented in Table 1 are 
by no means exhaustive, but are presented to show a range of ways in which cost estimation can be approached. The most appropriate cost estimation method is dependent on the nature of the utility strike cost indicator being estimated. The cost estimation methods in the literature can be grouped into two main classes, direct and indirect methods, where DC estimation techniques are the most extensively utilised methods since they are centred on market and measurable indicator costs (e.g. cost of labour and cost of repair). As stated by Gilchrist and Allouche (2005) in addition to Tsunokawa and Hoban (1997), commonly used DC estimation techniques comprise but are not limited to (a) loss of productivity, (b) human capital, (c) replacement cost, $(d)$ lane closure cost and (e) Spon's price book (or similar country equivalent). Conversely, IC estimation techniques are used in situations where the cost indicator does not have a market or measurable value in monetary terms (e.g. damage to brand image and traffic delay cost) and use of which allocates known market values to the indicator in question to arrive at an approximate cost. As stated by Gilchrist and Allouche (2005) in addition to Tsunokawa and Hoban (1997), commonly used IC estimation techniques comprise but are not limited to $(a)$ hedonic pricing, $(b)$ user delay cost and (c) Contingent valuation technique. However, as illustrated in the second column of Table 1, there will be instances when cost estimating one or more utility strike cost indicators will not be necessary based on other possible sources of cost estimation. This is because a source of cost estimation evidence will already be available and as such provides the DC estimation data sought for a specific utility strike cost indicator, as the availability or otherwise of cost estimation evidence is dependent on an existing paper trail.

\section{Phase 2: prepare, collect and analyse}

Here each individual utility strike case study comprises a 'full' study, in which convergence of cost estimation and multiple information sources is sought with respect to the evidence and deductions for the case.

A key feature of Figure 2 is the feedback loop (dashed line). These loops characterise a typical scenario, where important findings were discovered while analysing one of the individual case studies. Such a finding could necessitate re-examination of one or more of the study's initial cost estimation (utility strike cost indicators) and data collection protocols. At this stage, 'case design restructuring' ought to take place prior to moving forward with the study. This redesign could include modifications in the cost estimation and data collection protocols. Following this approach, the risk of distortions within the study is avoided, whereby 'external validity' is achieved through consistent replication of case design rules, 'reliability' is achieved through use of this consistent case study protocol and 'construct validity' is achieved through execution of the study on this basis, while collating multiple sources of evidence, which by consequence establish a robust chain of proof for resultant cost estimates.

\section{Phase 3: analyse and conclude}

The final phase involves cross-case synthesis of multiple cases. Aggregation of all the case study findings will result in totals for all cost estimates, for DC, IC and SC estimates.
These totals allow ratio analysis to be utilised with respect to $\mathrm{IC} /$ DC, SC/DC and IC + SC/DC ratios and act as an effective tool for identifying indicators of positive and negative utility strike cost trends. More importantly, this allows policymakers to gain insight into the differences over the supposed impact of utility strike incidents and their true impact to both the industry and society. The information that cost ratio trend analysis provides can be accumulated over time as with other initiatives currently ongoing in industry (e.g. CGA (2015) and Usag $(2015,2016)$ ). The ratio analysis additionally affords $(a)$ the ability to judge the efficiency of a company in a specific context concerning utility strikes; $(b)$ the ability to locate weakness of a company's operations concerning utility strikes; $(c)$ the ability to help formulate plans based on the understanding of past performance concerning utility strikes; and (d) the ability to compare performance over different years and compared with other companies within the same industry.

\section{Characteristics of the selected utility strike case studies}

This study focused on 16 case studies collected over 6 months (October 2014 to March 2015), where utility strikes were experienced and in which a mix of utility types and size of the associated projects were involved. Appendix 1 provides a detailed context on the 16 case studies. Several site visits where undertaken for data capture and application of the new approach methodology (see Figure 2 and the section headed 'Results and discussion').

Table 2 shows a breakdown of the different types of utility damaged in the 16 case studies, with electricity cables and gas pipelines being most represented. More information on the breakdown of utility strikes in the UK by type can be found in the paper by Metje et al. (2015) and the report by Usag (2016). Table 2 correspondingly shows the different types of excavation tools being used when a strike incident occurred. From Table 2 it is clear that mini diggers cause by far the highest number of utility strike incidents in the 16 case studies, which is in contrast to the findings by Metje et al. (2015), who found that hand tools were the most common, but the low number of cases presented herein may explain the differences. All but one (94\%) of the case studies reviewed had statutory drawings available before excavation, which were of variable quality, mostly presented in black and white, and often hard to read. These limitations were considered to be a significant contributory factor as to why the strike incidents occurred in the case studies. Of the statutory drawings available, six (37\%) accurately showed the location of utility services and seven (44\%) did not accurately show their location, while the accuracy of the remainder (three; 19\%) was not recorded.

Table 2 further shows whether the utilities were encased in concrete or directly buried in the ground. Services encased in concrete considerably increased the likelihood of a utility strike incident, as did cases in which services were not at the specified depth. Most companies in this study employ a safe dig best practice - that is, an exclusion zone for untraceable utility services. Where services cannot be detected by the use of a cable avoidance tool (Cat) scanner (e.g. 
Table 2. Characteristics of the 16 utility strike case studies

\begin{tabular}{|c|c|c|c|c|c|c|}
\hline $\begin{array}{l}\text { Case study } \\
\text { number }\end{array}$ & $\begin{array}{l}\text { Utility } \\
\text { type }\end{array}$ & $\begin{array}{l}\text { Excavation } \\
\text { tool used }\end{array}$ & $\begin{array}{l}\text { Cable/pipe } \\
\text { encased in } \\
\text { concrete }\end{array}$ & $\begin{array}{l}\text { Statutory drawings } \\
\text { available prior to } \\
\text { excavation }\end{array}$ & $\begin{array}{l}\text { Statutory } \\
\text { drawings } \\
\text { accurate }\end{array}$ & $\begin{array}{l}\text { Cat and Genny } \\
\text { (or similar) used } \\
\text { before excavation }\end{array}$ \\
\hline 1 & Water & Diamond drill & No & Yes & Yes & No \\
\hline 2 & $E-L V$ & Mini digger & N/A & Yes & N/A & No \\
\hline 3 & $E-L V$ & Mini digger & Yes & Yes & Yes & Yes \\
\hline 4 & Telecoms & Mini digger & No & Yes & Yes & N/A \\
\hline 5 & $E-L V$ & Mini digger & Yes & Yes & Yes & Yes \\
\hline 6 & $E-L V$ & Mini digger & No & Yes & N/A & Yes \\
\hline 7 & Gas LP & Mini digger & Yes & Yes & No & Yes \\
\hline 8 & $E-L V$ & 360 excavator & Yes & Yes & Yes & Yes \\
\hline 9 & $E-L V$ & $\begin{array}{l}\text { Air-powered } \\
\text { hand tool }\end{array}$ & Yes & Yes & No & Yes \\
\hline 10 & $E-L V$ & $\begin{array}{l}\text { Air-powered } \\
\text { hand tool }\end{array}$ & Yes & Yes & No & No \\
\hline 11 & Gas HP & Mini digger & No & Yes & Yes & Yes \\
\hline 12 & Gas LP & Mini digger & Yes & N/A & No & N/A \\
\hline 13 & $E-L V$ & Mini digger & Yes & Yes & No & Yes \\
\hline 14 & Gas HP & Mini digger & Yes & Yes & No & Yes \\
\hline 15 & Water & Mini digger & Yes & Yes & No & No \\
\hline 16 & $\mathrm{E}-\mathrm{HV}$ & Mini digger & Yes & Yes & No & No \\
\hline
\end{tabular}

$\mathrm{E}-\mathrm{HV}$, electricity high voltage; E - LV, electricity low voltage; Gas HP, gas high pressure; Gas LP, gas low pressure

${ }^{a}$ Cat and Genny (signal generator) (PAS 128:2014 (BSI, 2014), level 2 equivalent)

polyethylene (PE) gas and water pipes, pot-ended electricity cables), where no as-built information was available and where there was no visible indication of the presence of buried services from the surface (i.e. valves or chambers), an automatic $600 \mathrm{~mm}$ red exclusion zone is used when excavating either side of the expected service location regardless of depth. The methodological approach described in the section headed 'Methodological approach' is applied in the section headed 'Results and discussion' to the 16 utility strike case study incidents.

\section{Results and discussion}

Utility strike incidents are unique with respect to the wider adverse impacts that each one causes - that is, their true cost. Table 3 provides a summary of all the case study findings (presented in Table 2) and is intended to give broad indications or estimations of the costs of utility strikes. It therefore provides a baseline for estimating potential costs and brings to focus the true cost of strike incidents. However, details of both the works carried out to rectify the situation once the strike has occurred and the context - the surrounding urban fabric and activities and the nature of the disruption to them - are necessary to understand the cost calculations and how they might be translated to other sites where utility strikes have occurred.

Accordingly, Appendix 1 (Table 4) provides the essential details for the case studies, although even with this detail, extrapolation and translation will remain at best approximate because every incident and subsequent activities and impacts will be to some degree unique. This is where the difficulty arises in making a case for changes in practice and governance - individual cases provide an insufficiently strong evidence base for far-reaching change. The current paper has measured factual impacts and aims to provide the missing robustness to this evidence base, being founded on a relatively large number of cases. Importantly the strength of this approach makes a compelling case for accurate detection of buried utilities in addition to the development of safe digging practices and the use of alternative working practices.

Nevertheless, engineering judgement is required to diagnose the full impacts and take into account fully the context in which the disruption has occurred and hence enable the findings to be translated to other situations. In this respect, the apparently highly approximate accounting of additional impacts (i.e. those due the adverse impacts of queuing traffic, such as noise pollution, air pollution, loss of business and health and safety issues) is helpful, since adjustment of the evidence base can be made on the basis of the contextual information provided and equally allowance can be made in determining costs for any other particular case under consideration. The use of engineering judgement is to be encouraged, therefore, but on the understanding that the assumptions used in arriving at this judgement are made explicit and therefore the evidence on which the judgement is made is wholly transparent.

The $100 \%$ stacked column graph in Figure 3 compares the percentage that each cost category (direct, indirect and social) contributes to the total true cost to emphasise the different proportions. The ratio expresses the mathematical relationship between IC, SC and DC as expressed in the equation

1. utility strike cost ratio $=(\mathrm{IC}+\mathrm{SC}) / \mathrm{DC}$

It can be seen that the $\mathrm{DC}$ of the remedial works does not account for half the total cost in any of the case studies. It should be noted 
Table 3. Summary of case study utility strike costs - direct, indirect and social

\begin{tabular}{|c|c|c|c|c|c|c|c|c|}
\hline Case study & Strike cost indicators estimated ${ }^{a}$ & $\begin{array}{l}\text { Utility } \\
\text { type }\end{array}$ & DC: $\mathbf{f}$ & IC: $\mathbf{f}$ & SC: $f$ & $\begin{array}{l}\text { Ratio: } \\
\text { IC/DC }\end{array}$ & $\begin{array}{l}\text { Ratio: } \\
\text { SC/DC }\end{array}$ & $\begin{array}{l}\text { Ratio: IC + } \\
\text { SC/DC }\end{array}$ \\
\hline 1 & DC2, DC4, DC6, DC7, IC4 & Water & 750 & 2000 & - & $2 \cdot 67$ & - & - \\
\hline 2 & $D C 2, D C 4, D C 6, D C 7, I C 4$ & $E-L V$ & 1675 & 2000 & - & $1 \cdot 19$ & - & - \\
\hline 3 & DC2, DC4, DC6, DC7, IC4 & $E-L V$ & 1400 & 2000 & - & $1 \cdot 43$ & - & - \\
\hline $4^{b}$ & DC2, DC4, DC6, DC7, SC1 & Telecoms & 680 & - & 602698 & - & $886 \cdot 32$ & - \\
\hline $5^{b}$ & DC2, DC4, DC6, DC7, SC1 & $E-L V$ & 1275 & - & 41128 & - & $32 \cdot 26$ & - \\
\hline 6 & DC2, DC4, DC6, DC7, IC4 & $E-L V$ & 1780 & 2000 & - & $1 \cdot 12$ & - & - \\
\hline 7 & DC2, DC4, DC6, DC7, IC4 & Gas LP & 1000 & 2000 & - & 2 & - & - \\
\hline 8 & $D C 2, D C 4, D C 6, D C 7, I C 4$ & $E-L V$ & 969 & 2000 & - & $2 \cdot 06$ & - & - \\
\hline 9 & $D C 2, D C 4, D C 6, D C 7, I C 4$ & $E-L V$ & 2500 & 5500 & - & $2 \cdot 2$ & - & - \\
\hline 10 & DC2, DC4, DC6, DC7, IC4 & $E-L V$ & 4000 & 5000 & - & $1 \cdot 25$ & - & - \\
\hline $11^{c}$ & $\begin{array}{l}\text { DC1, DC2, DC4, DC5, DC6, DC7, IC4, SC1, } \\
\text { SC3, SC4, SC6 }\end{array}$ & Gas HP & 7800 & 105000 & 173032 & $13 \cdot 46$ & $22 \cdot 18$ & $35 \cdot 65$ \\
\hline $12^{c}$ & DC1, DC2, DC4, DC5, DC6, DC7, IC4, SC1 & Gas LP & 3475 & 6000 & 82256 & $1 \cdot 73$ & $23 \cdot 67$ & $25 \cdot 40$ \\
\hline 13 & $\begin{array}{l}\text { DC2, DC3, DC4, DC6, DC7, IC3, IC5, IC8, } \\
\text { SC2 }\end{array}$ & $E-L V$ & 7500 & 10000 & 146500 & $1 \cdot 33$ & $19 \cdot 53$ & $20 \cdot 90$ \\
\hline 14 & $\begin{array}{l}\text { DC1, DC2, DC3, DC4, DC5, DC6, DC7, IC3, } \\
I C 4, I C 5, I C 6, I C 8\end{array}$ & Gas HP & 5000 & 76640 & - & $15 \cdot 33$ & - & - \\
\hline 15 & $\begin{array}{l}\text { DC1, DC2, DC4, DC6, DC7, IC4, IC5, IC8, } \\
\text { IC9, SC2, SC3, SC6 }\end{array}$ & Water & 10000 & 25000 & 414779 & $2 \cdot 5$ & $41 \cdot 48$ & $43 \cdot 98$ \\
\hline 16 & $\begin{array}{l}\text { DC1, DC2, DC3, DC4, DC6, DC7, IC4, IC5, } \\
\text { SC2 }\end{array}$ & $\mathrm{E}-\mathrm{HV}$ & 10000 & 75000 & 70500 & $7 \cdot 5$ & $7 \cdot 05$ & $17 \cdot 55$ \\
\hline $\begin{array}{l}\text { Total and } \\
\text { averages }^{d}\end{array}$ & - & - & 59804 & 220140 & 1530893 & $3 \cdot 68$ & $25 \cdot 60$ & $29 \cdot 28$ \\
\hline
\end{tabular}

$\mathrm{E}-\mathrm{HV}$, electricity high voltage; E - LV, electricity low voltage; Gas HP, gas high pressure; Gas LP, gas low pressure

${ }^{a}$ Refer to Table 1 for more details

${ }^{b}$ Case studies where traffic delays experienced were quantified without a $40 \%$ additional cost as shown in Appendix 2

${ }^{c}$ Case studies where traffic delays experienced were quantified with a $40 \%$ additional cost as shown in Appendix 2, to account for adverse environmental impacts experienced

${ }^{\mathrm{d}}$ The totals and averages are calculated for all 16 utility strike case studies

that by normalising the costs for each case study with respect to the total cost (see Figure 3), information on the size of the costs is lost. Based on the costs derived from each case study, it is possible to determine the ratio of indirect and socials cost to the DCs incurred

$$
\begin{aligned}
\text { utility strike cost ratio } & =(\mathrm{IC}+\mathrm{SC}) / \mathrm{DC} \\
& =(220140+1530893) / 59804 \\
& \approx 29
\end{aligned}
$$

2.

Thus, indirect and SCs are on average 29 times larger than the DC of repair incurred to resolve the strike. It could be argued that the robustness of this ratio could be improved with the addition of more case studies, yet the ratios are almost universally likely to prove underestimates of the full impacts of the works.

The more immediate observation from Figure 3 is that the quantified true costs of utility strikes in the UK is far more than what was previously thought on the basis of industry calculations; see the paper of Metje et al. (2015). As Figure 3 shows, the DC of remedial works, which is consistently at present the only recorded cost for strike incidents, is often a small proportion of the true cost and is sometimes almost negligible in comparison (e.g. case studies 4,5 and 11-16). In practice, if the proposed methodology was applied and the utility strike cost ratio (29:1) was extrapolated to all utility strikes in the UK, the case for far greater emphasis on preventative measures would be so overwhelming, leading to changes in both governance and industry practices (with 60000 incidents occurring annually in the UK (ICE, 2017), and a conservative estimate of $£ 500$ of direct repair costs (Metje et al., 2015 ) would result in a total cost of $£ 870$ million).

It is clear from the case study findings that road traffic congestion is the main contributor to several of the SCs identified in this study - in particular road user delay, delay to train commute times and the costs to businesses from lost productivity and business income (see Table 3 and the report of Makana et al. (2016b) for more details). Yet to emphasise the point made earlier, while the specific impact of utility strikes on road user delay costs has been investigated in some detail, a deeper understanding of other congestion-related costs would strengthen the evidence base and the case for change in favour of minimising disruption to citizens. An obvious counter argument for change is that the cost of street works might rise, and this cost would be passed onto the customers, yet this misses the essential point made by Hayes et al. (2012) that there is 'one customer' in all this - the ICs and SCs are ultimately paid by the same citizens who receive a marginal saving by avoiding the costs of the 'externalities' (i.e. the ICs and SCs) of remedial street works on their utility bills. The logical conclusion of this line of thinking, therefore, is that citizens 


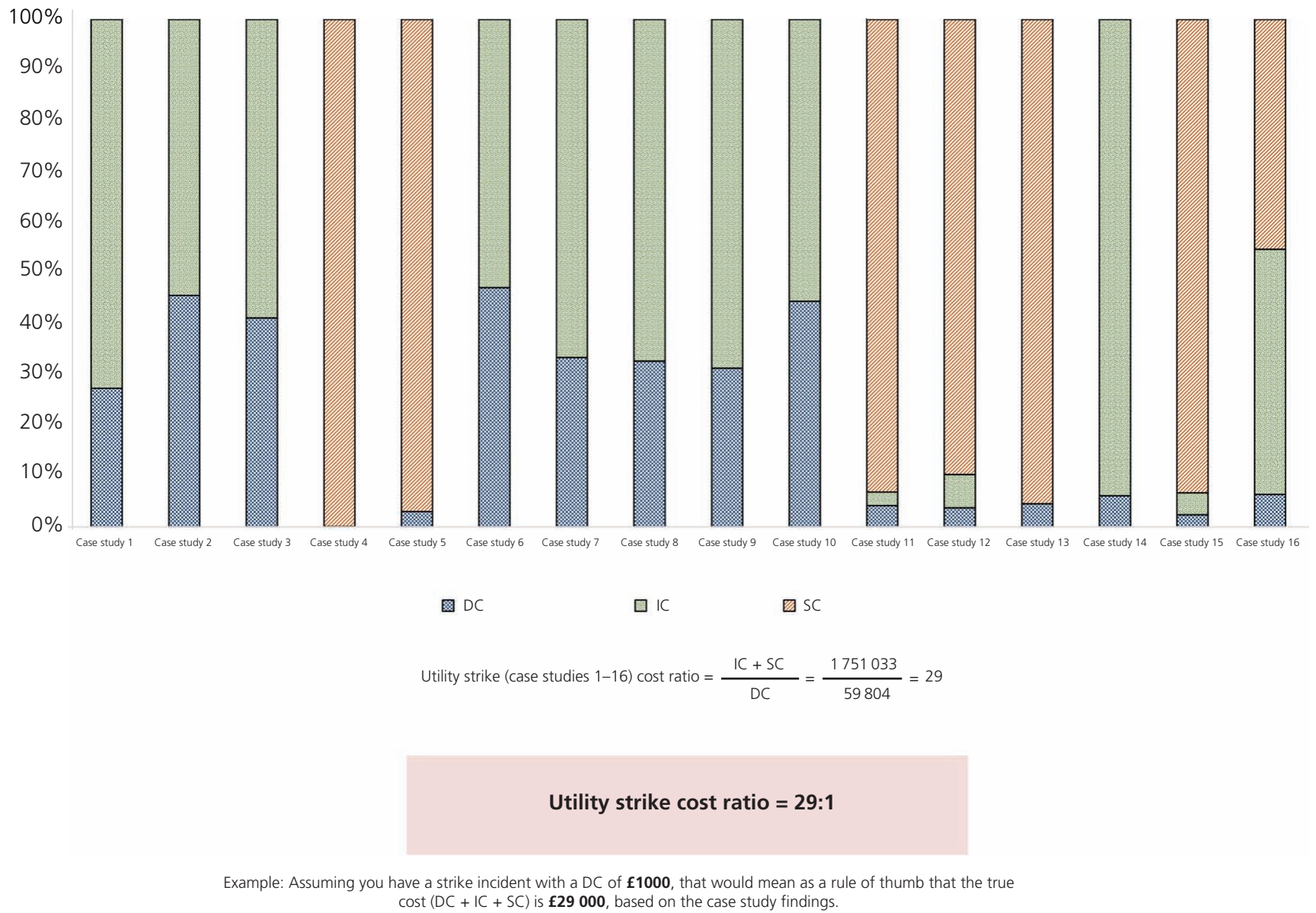

Figure 3. Utility strike cost ratio from the 16 case studies

would almost certainly welcome a small extra cost invested to reduce greatly the likelihood of utility strikes rather than paying the far larger ICs and SCs of the consequences of not doing so. Moreover, this would lead to hidden, or uncosted, benefits such as a general enhancement of citizen well-being (Leach et al., 2016)

A different approach is needed to move thinking away from the traditional views of utility strike impacts centred on the DC of repair and more importantly make the business case for the upfront investment required by PAS 128:2014 surveys (BSI, 2014). The new approach methodology developed herein helps to bridge this 'gap in knowledge' by taking a view beyond the direct construction works (and costs) to include impacts on the three pillars of sustainability: the economy, the environment and society. Although some social and even some environmental costs (in spite of the recent work on natural capital impacts (Natural England, 2016)) are difficult to monetise, such a shift in thinking relies on attempts to cost estimate in monetary terms the true cost - that is, make explicit the full impact of a utility strike incident using a common baseline.

\section{Conclusions}

This paper describes the development of the new approach methodology - a novel multi-case study approach to cost estimation of the true cost of utility strike incidents. The methodology was applied as a proof of concept to 16 utility strike case study incidents in dense urban environments, this representing an unprecedented evidence base in the published literature and one that therefore has the potential for a profound impact on policy and governance.

The overall true cost ratio, determined by summing the primary ICs and SCs deriving from remedial works following a utility strike and comparing them to the DCs of the remedial works, when averaged out over all the 16 case studies, amounted to 29:1. This finding highlights the very considerable cost of utility strikes beyond DCs. However, it should be noted that since the case studies all occurred in dense urban areas, it is likely that this cost ratio is an underestimate, since additional adverse effects that utility strikes can have on the environment, citizens' quality of life, the operation of businesses and so on will not have been adequately included.

The size of the discrepancy between the DCs of remedial works, which are typically the only costs recorded by the utilities industry, and the 'total costs' has been emphasised by normalising the different costs on a $100 \%$ stacked column graph for each case study with respect to the total cost. The DC accounts for less than 
$50 \%$ of the total cost in all the case studies, and in half of the cases, it forms an almost negligible proportion ( $6 \%$ or less). Lack of knowledge of where utilities were buried and utilities being encased in concrete contributed to $75 \%$ of the 16 strike case study incidents, implying that improved survey practices could have helped to avoid the strikes occurring. Moreover, the separate indirect to direct, and social to direct, cost ratios provide important evidence on which to base improved site practices.

The successful application of the methodology on the 16 utility strike case studies demonstrates that it is a suitable tool for facilitating improved decision-making based on an economic imperative for utilities management and planning. The evidence base that this research has created, and in particular the underpinning details of the strike incidents, remedial works and urban context in which they were carried out, provides an invaluable resource against which to make engineering judgements for the assessment and cost estimation of the true cost of utility strike incidents for any particular case or site elsewhere. It also enables refinement, again using engineering judgement, of the calculations, which have deliberately used a simple and transparent methodology in each case. More importantly, it provides the basis for political interventions and a change in the governance of street works to bring about a better, and cheaper, outcome for the citizens who benefit from the utility services and an undisrupted transport and urban environment.

\section{Acknowledgements}

The authors gratefully acknowledge the funding provided by the UK Engineering and Physical Sciences Research Council (EPSRC) and the Economic and Social Sciences Research Council for Infrastructure BUsiness Models, Valuation and Innovation for Local Delivery (iBuilD) (Grant Reference EP/K012398/1) and by EPSRC for Assessing the Underworld (Grant Reference EP/K021699/1).

\section{Appendix 1}

Table 4. Contextual information for the case studies (continued on next page)

$\begin{array}{lll}\text { Case } & \text { Utility strike context } & \text { Utility strike incident }\end{array}$

\section{number}

There was a error of judgement and a failure to observe fully the permit to dig procedure, and safe digging' practices were not observed on a construction site adjacent a bridge. The remedial works did not unduly disturb traffic

The night shift supervisor noticed at about 2.30 a.m. that traffic warning sign bulb had gone out. He went to investigate and discovered a damaged cable and stopped works. The operator did not follow the safe system of work. Works in the immediate area were suspended and sandbags were used to make the area safe temporally. The remedial works did not unduly disturb traffic

Workmen were pulling out concrete bedding from kerbs. A cable feeding a lit street sign was encased within the concrete. This came out with the concrete, and a pop sound was heard. The cable was known about due to a taped-off electrical pole socket nearby in the footpath. The remedial works did not unduly disturb traffic

Prior to opening the tunnel to traffic, it was confirmed by London Streets Tunnels Operation Centre (LSTOC) that they had a fault on communication to the gantry on the westbound tunnel and could not control the matrix signs on the gantry, which was operated manually to allow the tunnel to be opened to the public. Further investigation revealed that a communication cable that was believed to be part of the disconnected cables was cut. It was later found to be the live communication control cable of the western gantry. The remedial works disturbed traffic flow in the tunnel and surrounding area for near enough a full day

$5 \quad$ While attempting to remove a street lighting control cabinet, an LV signal cable was heard sparking in the ground. Despite service plans being available and a Cat scan being carried out, the cable was not identified as it was encased in concrete. The remedial works disturbed traffic in the area for $4 \mathrm{~h}$

The operative was breaking/excavating behind kerbs to install a duct for a traffic signal - an LV cable was struck $150 \mathrm{~mm}$ below footpath surface in hard ground. The remedial works did not unduly disturb traffic

$7 \quad$ The gas pipe was buried approximately $150 \mathrm{~mm}$ below the surface material. It was not identified on statutory plans or identified during scanning due to the plastic pipe material. The remedial works did not unduly disturb traffic
While diamond drilling concrete slab to enable quiet demolition, the core drill cut through a $25 \mathrm{~mm}$ water supply

When excavating the operative lost control of the mini digger and struck an LV street light cable

When pulling out concrete kerbs, an electrical lit LV street sign cable embedded in concrete was snagged

Human error - a live communication cable was accidentally cut

The contractor had to contact LSTOC for an update on any faults on the system which will allow time to rectify them before the end of the shift

The LV cable was encased in concrete and was not detected when using a Cat. As the control cabinet was moved, it became apparent that the cable had been damaged by a mini digger

When installing ducting, the operative lost control of the pneumatic spade and struck an exposed LV cable

During trial hole excavation using a hand breaker, an LP gas pipe was accidentally struck. The works were stopped until the gas pipe was reinstated 


$\begin{aligned} & \text { Case } \\ & \text { study } \\ & \text { number }\end{aligned}$
Utility strike context
The cable was identified on statutory plans, and a Cat was used to verify this.
A lump of concrete was lifted using a machine when the duct and cable wer
damaged. The remedial works did not unduly disturb traffic
Apparatus undertakers asked the contractor to dig a trial hole around an
existing 6" (152 mm) water pipe along a footpath. This trial hole was
needed to determine a tie-in location for a new rider main. The tie-in
works were planned for night time. The work started at 2 a.m. The
remedial works did not unduly disturb traffic

The service in question was not shown on the drawing accompanying the permit to dig. Prior to the possible cable strike, there was a black cable in ducting uncovered, of which the ducting appeared to have been damaged. This was also not on the drawing. The remedial works did not unduly disturb traffic

11 Work was being carried out to divert an existing 18" (0.457 m) HP gas distribution main prior to further works. Uncompacted reinstatement material from previous work carried out by the contractor, which had been supported by this shoring, pressed against the top number of sheet piles, pivoting them and creating a gap which allowed a small volume of material to slump into the excavation. The remedial works severely disturbed traffic and businesses in the area for approximately 3 weeks

12 Two utility operatives were excavating a trench at a busy junction in order to lay a duct for a future HV cable when a strike incident happened. The remedial works disturbed traffic in the area

While breaking out the slab, a cable was struck by a breaker, causing a flash of light/fire to be emitted. It was soon after found that as a result of the utility strike, power to businesses on two adjacent roads was lost from 9.30 a.m. to 5.10 p.m. (c. 6.5 h). The remedial works did not unduly disturb traffic

While carrying out excavation works for the construction of the mass retaining wall on a busy street, a HP gas main was exposed adjacent to the excavation. The remedial works did not unduly disturb traffic

Information from the statutory undertaker proved to be incorrect on a construction site. The drawing identified the water main to be at $1.3 \mathrm{~m}$ below ground level and was subsequently struck at $1.6 \mathrm{~m}$ below ground level. The remedial works disturbed underground train services as well as water supply to two businesses in the area

Inaccurate buried service information was utilised to plan and implement excavation works on a construction site, resulting in an inadequate risk assessment and the development of associated control measures. The remedial works affected power in the local area for half an hour, and a nearby theatre performance was interrupted

\section{Utility strike incident}

While excavating to lay cable ducts, a $4 \mathrm{~mm}$ LV street lighting cable was damaged

There was $60 \mathrm{~mm}$ depth of paving and below these slabs approximately $300 \mathrm{~mm}$ of concrete. This meant that operatives had to use an air-powered breaker to excavate the trial hole. While breaking the concrete, a $50 \mathrm{~mm}$ black LV duct was breached by the airpowered breaker. There was no spark as the cable was not live. The contractor halted the trial hole until a repair was undertaken. UK Power Networks came to site at 3 a.m. and isolated the cable permanently by installing a shrink wrap end cap which proved the cable was dead

The LV cable in question was surrounded in a sharp sand and cement mixture with no indications such as ducting, sand or hazard tape present. It was struck using a pneumatic spade

While a $12 \mathrm{~m}$ length of $500 \mathrm{~mm}$ PE HP gas main was being lowered into the excavation, a section of shoring failed

Considering the LP gas pipe to be dead, following checks undertaken by utility operatives from the subcontractor for the main contractor, the operatives decided to break the pipe. The pipe was subsequently found to be live, resulting in uncontrolled loss of gas. The utility operatives from the subcontractor attended the site to seal the broken pipe temporally. A cordon was placed around the work compound to control members of the public, and the local restaurant was warned

While carrying out excavation works to determine a route for the installation of the $180 \mathrm{~mm}$ water main, an LV cable was struck by a handheld breaker

A floor saw was used to cut the existing asphalt, followed by the breakout of the underlying concrete road base. During the breakout, the gas main was exposed and punctured using a mini digger

A $100 \mathrm{~mm}$ inner dia. water main was fractured with a mini digger requiring repair. Minor water damage and clean-up were required up to the train platform level

A handheld hydraulic breaker point pierced the outer protective layer of an $11 \mathrm{kV} \mathrm{HV}$ cable, resulting in damage to one core resulting in a short circuit 


\section{Appendix 2}

\section{Detailed traffic delay calculations}

Step 1: Determine which traffic control plan replicates the traffic disruptions for the case study area under examination (see the paper of Tighe et al. (1999) for examples), and the underlying assumptions associated with it (e.g. lane width, length of detour, partial/full closure of one lane, use of flag person, use of signalised zone and delays associated only with a speed reduction)

Step 2: Determine the total time duration caused by the traffic disruptions for the case study under examination.

Step 3: Determine the average annual daily traffic (AADT) for the case study area under examination. Ordinarily, the transport authority in the country in question retains AADT data. In the UK, AADT for any given road can be determined through the Department for Transport's traffic count online database (Leduc, 2008). The AADT on a road segment can alternatively be estimated by using Equation 3 where no official traffic count data exists.

3. $\mathrm{AADT}_{S}=\sum_{j=1}^{365} \frac{\mathrm{TF}_{s, j}^{24}}{365}$

where $\mathrm{TF}_{s, j}^{24}$ is the $24 \mathrm{~h}$ traffic flow on segment $s$ at day $j$.

Step 4: Based on the traffic control plan $(1,2$ or 3 , chosen after Tighe et al. (1999); see below) and total duration time of traffic disruptions experienced as a result of the utility strike incident (equations are provided for 40, 50, 80, 100, 160 and $200 \mathrm{~h}$ by Tighe et al., 1999; the values calculated by the equations can be summed, and thus a combination of the equations can be used), the appropriate equation(s) can now be selected to determine the cost associated with traffic disruptions. The equations in Tables 5-7 are for a total disruption time of $80 \mathrm{~h}$ using different traffic control plans.

Traffic control plan 1 refers to full closure of one lane and the use of a flag person or signalised zone to allow traffic alternately to bypass the roadworks and the assumption that the associated delay will be a queuing delay. Traffic control plan 2 refers to

Table 5. Traffic control plan $1-80 \mathrm{~h}$

\begin{tabular}{|lccc|}
$\begin{array}{l}\text { Lane } \\
\text { width: } \mathbf{m}\end{array}$ & $\begin{array}{c}\text { Utility strike } \\
\text { duration: } \boldsymbol{h}\end{array}$ & Equation & $\boldsymbol{R}^{\mathbf{2}}$ \\
\hline 3.75 & 80 & $\begin{array}{l}\log (\cos \mathrm{t})=0.00022 \mathrm{AADT} \\
+3.5556\end{array}$ & 0.982 \\
& & &
\end{tabular}

Table 6. Traffic control plan $2-80 \mathrm{~h}$

\begin{tabular}{|lccc|}
$\begin{array}{l}\text { Lane } \\
\text { width: } \mathbf{m}\end{array}$ & $\begin{array}{c}\text { Utility strike } \\
\text { duration: } \boldsymbol{h}\end{array}$ & Equation & $\boldsymbol{R}^{\mathbf{2}}$ \\
\hline 3.75 & 80 & $\begin{array}{l}\log (\cos t)=0.00038 \text { AADT } \\
+1.8098\end{array}$ & 0.893 \\
& & & \\
\hline
\end{tabular}

Table 7. Traffic control plan $3-80 \mathrm{~h}$

\begin{tabular}{|lccc|}
$\begin{array}{l}\text { Lane } \\
\text { width: } \mathbf{m}\end{array}$ & $\begin{array}{c}\text { Utility strike } \\
\text { duration: } \mathbf{h}\end{array}$ & Equation & $\boldsymbol{R}^{\mathbf{2}}$ \\
\hline 3.75 & 80 & $\begin{array}{l}\log (\cos t)=0.00051 \text { AADT } \\
+0.8780\end{array}$ & 0.899 \\
& & &
\end{tabular}

traffic diverting over a shoulder or being funnelled into a narrower lane to bypass the roadworks, so the traffic is still able to proceed and delays would be associated with speed reductions and queuing in times of high flow. Traffic control plan 3 refers to full closure of the road and implementation of a traffic diversion.

Step 5: Having calculated the delay time in step 4, it is proposed to increase the delay by $40 \%$ using a 'rule of thumb' approximation for utility strikes in urban areas with a high population density to account for the adverse impacts of queuing traffic related to noise pollution, air pollution, loss of business and health issues (Goodwin, 2005; Lee et al., 2005; Weisbrod et al., 2003). This rule of thumb should be used where the corresponding data for quantifying these separate additional costs as a result of the strike incident cannot be accessed (see the publication of McMahon et al. (2005) for additional ICs and SCs that may arise as a result of street works). However, this is where engineering judgement can be brought into consideration to take account of the context: roadworks that have to be extended in an urban street adjacent to a school playground and close to a school entrance with a heavy pedestrian footfall would attract, for example, a greater multiplier for the additional impacts.

Step 6: It should be noted that the equations quoted by Tighe et al. (1999) are computed in US dollars. If these equations are utilised in other jurisdictions, the calculated cost value for traffic disruption should be subject to an appropriate currency conversion.

\section{Example illustrative calculations}

For the new approach, utility strike cost estimation methodology, traffic delay quantification will be illustrated in a concise manner herein through case study 11.

Step 1: Traffic control plan 3 (after Tighe et al. (1999)) was implemented as a result of the utility strike incident.

Step 2: The traffic delay impact was 3 weeks in total as a result of the utility strike incident. Assuming that Sunday trading laws in the UK make Sunday a half day based on a $10 \mathrm{~h}$ working day, the traffic delay impact is for $6.5 \mathrm{~d} /$ week.

total traffic delay due to strike incident 4. $=(10 \times 6 \cdot 5) \times 3=195 \mathrm{~h}(\sim 200 \mathrm{~h})$

Step 3: AADT for the case study area under examination $=8000$ 
Step 4: Traffic control plan 3 with a total time duration of $\sim 200 \mathrm{~h}$ for a road with a lane width of $3.75 \mathrm{~m}$ results in the following equation

$$
\begin{aligned}
\log (\text { cost }) & =0 \cdot 00051 \mathrm{AADT}+1 \cdot 1690 \\
& =(0 \cdot 00051 \times 8000)+1 \cdot 1690 \\
5 . \quad \mathrm{cost} & =10^{[(0 \cdot 00051 \times 8000)+1 \cdot 1690]}=\$ 177418
\end{aligned}
$$

Step 5: To account for additional impacts of queuing traffic in a dense built-up area for which no data were available, the rule of thumb of $40 \%$ of the total traffic delay time cost is applied

\section{6. $200 \mathrm{~h} \times 40 \%=80 \mathrm{~h}$ (additional costs)}

Traffic control plan 3 with a total time duration of $80 \mathrm{~h}$ results in the following equation

$$
\begin{aligned}
\log (\cos t) & =0 \cdot 00051 \mathrm{AADT}+0 \cdot 8780 \\
& =(0 \cdot 00051 \times 8000)+0 \cdot 8780 \\
7 . \quad \operatorname{cost} & =10^{[(0.00051 \times 8000)+0.8780]}=\$ 90782
\end{aligned}
$$

Step 6: Convert to pounds given that the case study under examination is UK centric $(£ 1=\$ 1 \cdot 55-($ conversion rate taken in April 2015, at the time of this study))

8.

$$
\text { traffic delay } \operatorname{cost}(£)=(177418+90782) / 1 \cdot 55
$$

$$
=£ 173032
$$

\section{REFERENCES}

AECOM (2017) Spon's Civil Engineering and Highway Works Price. Taylor \& Francis, Abingdon, UK.

ASCE (American Society of Civil Engineers) (2002) Standard Guideline for the Collection and Depiction of Existing Subsurface Utility Data. ASCE, Reston, VA, USA, CI/ASCE 38-02.

Bell LC, Brandenburg SG, Ogle JH and Reinke M (2014) Evaluation of Utility Relocation Costs and Best Management Practices. South Carolina Department of Transportation, Columbia, SC, USA, FHWA-SC-14-01.

Bernold LE (2003) Economic model to optimize underground utility protection. Journal of Construction Engineering and Management 129(6): 645-652, https://doi.org/10.1061/(ASCE)0733-9364(2003) 129:6(645).

Brady KC, Burtwell M and Thomson JC (2001) Mitigating the Disruption Caused by Utility Street Works. TRL Limited, Crowthorne, UK.

Broome J and Perry J (2002) How practitioners set share fractions in target cost contracts. International Journal of Project Management 20(1): 59-66, https://doi.org/10.1016/S0263-7863(00)00035-1.

BSI (2014) PAS 128:2014: Specification for underground utility detection, verification and location. BSI, London, UK.

Çelik T, Kamali S and Arayici Y (2017) Social cost in construction projects. Environmental Impact Assessment Review 64: 77-86, https://doi.org/ 10.1016/j.eiar.2017.03.001.
CGA (Common Ground Alliance) (2015) CGA DIRT Analysis and Recommendations 2015. CGA, Alexandria, VA, USA

Clarke BG, Magee D, Dimitrova V et al. (2017) A decision support system to proactively manage subsurface utilities. In International Symposium for Next Generation Infrastructure, 11-13 Sep 2017. Institution of Civil Engineers, London, UK, pp. 99-108.

Gilchrist A and Allouche EN (2005) Quantification of social costs associated with construction projects: state-of-the-art review. Tunnelling and Underground Space Technology 20(1): 89-104, https:// doi.org/10.1016/j.tust.2004.04.003.

Goodrum PM, Kari F, Smith A, Slaughter B and Jones CN (2006) An Analysis of the Direct and Indirect Costs of Utility and Right-of-way Conflicts on Construction Roadway Projects. Kentucky Transportation Center, College of Engineering, University of Kentucky, Lexington, KY, USA, p. 215, Research Report KTC-06-19/SPR-293-05-1F.

Goodrum P, Smith A, Slaughter B and Kari F (2008) Case study and statistical analysis of utility conflicts on construction roadway projects and best practices in their avoidance. Journal of Urban Planning and Development 134(2): 63-70, https://doi.org/10.1061/(ASCE)07339488(2008)134:2(63).

Goodwin P (2005) Utilities Street Works and the Cost of Traffic Congestion. Centre for Transport and Society, University of the West of England, Bristol, UK.

Hayes R, Metje N, Chapman DN and Rogers CDF (2012) Sustainability assessment of UK streetworks. Proceedings of the Institution of Civil Engineers - Municipal Engineer 165(4): 193-204, https://doi.org/10. 1680/muen.12.00004

Hojjati A, Jefferson I, Metje N and Rogers CDF (2017) Embedding sustainability criteria into pre-appraisal of underground utility for future cities. Urban Design and Planning, Proceedings of the Institution of Civil Engineers 170(6): 258-271, https://doi.org/10.1680/jurdp.17.00023.

Hojjati A, Jefferson I, Metje N and Rogers CDF (2018) Sustainability assessment for urban underground utility infrastructure projects. Proceedings of the Institution of Civil Engineers - Engineering Sustainability 171(2): 68-80, https://doi.org/10.1680/jensu.16.00050.

Hunt DVL, Nash D and Rogers CDF (2014) Sustainable utility placement via multi-utility tunnels. Tunnelling and Underground Space Technology 39: 15-26, https://doi.org/10.1016/j.tust.2012.02.001.

Hunt DVL, Makana LO, Jefferson I and Rogers CDF (2016) Liveable cities and urban underground space. Tunnelling and Underground Space Technology 55: 8-20, https://doi.org/10.1016/j.tust.2015.11.015.

ICE (Institution of Civil Engineers) (2017) Mock Trial: Service Strike, London. ICE, London, UK. See https://www.aps.org.uk/events/icemock-trial-service-strike (accessed 01/02/2017).

Jung YJ and Sinha SK (2007) Evaluation of trenchless technology methods for municipal infrastructure system. Journal of Infrastructure Systems 13(2): 144-156, https://doi.org/10.1061/(ASCE)1076-0342 (2007)13:2(144).

Kraus E, Obeng-Boampong K and Quiroga C (2012) Utility investigation trends in Texas. Transportation Research Record 2309: 209-217, https://doi.org/10.3141/2309-20.

Leach JM, Braithwaite PA, Lee SE et al. (2016) Measuring urban sustainability and liveability performance: the City Analysis Methodology. International Journal of Complexity in Applied Science and Technology 1(1): 86-106.

Leduc G (2008) Road Traffic Data: Collection Methods and Applications. Institute for Prospective Technological Studies, Seville, Spain, Working Papers on Energy, Transport and Climate Change no. 1.

Lee HS, Ryu HG, Yu JH and Kim JJ (2005) Method for calculating schedule delay considering lost productivity. Journal of Construction Engineering and Management 131(11): 1147-1154, https://doi.org/10. 1061/(ASCE)0733-9364(2005)131:11(1147).

Lew JJ (2000) Cost Savings on Highway Projects Utilizing Subsurface Utility Engineering. Federal Highway Administration, Washington, USA. 
Litman T (2017) Smart Congestion Relief: Comprehensive Analysis of Traffic Congestion Costs and Congestion Reduction Benefits. Victoria Transport Policy Institute, Victoria, BC, Canada.

Makana LO, Jefferson I, Hunt DVL and Rogers CDF (2016a) Assessment of the future resilience of sustainable urban sub-surface environments. Tunnelling and Underground Space Technology 55: 21-31, https://doi org/10.1016/j.tust.2015.11.016.

Makana LO, Metje N, Jefferson I and Rogers CDF (2016b) What Do Utility Strikes Really Cost? School of Civil Engineering, University of Birmingham. Birmingham, UK, p. 84. See http://bit.ly/2flQPGt (accessed 20/06/2018)

Makana LO, Metje N and Rogers CDF (2017) Mapping and assessing the underworld: a novel approach to utility management in smart and sponge cities. 5th International Conference on Utility Management and Safety (ICUMAS 2017), 29- 31 March, Kowloon, Hong Kong, pp. 136-146.

Matthews JC, Allouche EN and Sterling RL (2015) Social cost impact assessment of pipeline infrastructure projects. Environmental Impact Assessment Review 50: 196-202, https://doi.org/10.1016/j.eiar.2014. 10.001.

McMahon W, Evans M, Burtwell MH and Parker J (2005) The Real Costs of Street Works to the Utility Industry and Society. UK Water Industry Research, London, UK

Metje N, Atkins PR, Brennan MJ, Chapman DN et al. (2007) Mapping the underworld - state-of-the-art review. Tunnelling and Underground Space Technology 22(5): 568-586, https://doi.org/10.1016/j.tust.2007. 04.002 .

Metje N, Ahmad B and Crossland SM (2015) Causes, impacts and costs of strikes on buried utility assets. Proceedings of the Institution of Civil Engineers - Municipal Engineer 168(3): 165-174, https://doi.org/10. 1680/jmuen.14.00035.

Moran J, Torbaghan ME and Burrow MPN (2017) Estimating the benefits of joint occupation for street works in the UK. Infrastructure Asset Management 4(4): 115-127, https://doi.org/10.1680/jinam.17. 00007.

Najafi M and Gokhale S (2005) Social costs of utility construction: a life cycle cost approach. In Trenchless Technology: Pipeline and Utility Design, Construction, and Renewal. McGraw-Hill Education, New York, NY, USA, pp. 23-42.

Najafi M and Kim KO (2004) Life-cycle-cost comparison of trenchless and conventional open-cut pipeline construction projects. Proceedings of the ASCE Pipeline Division Specialty Congress - Pipeline Engineering and Construction, San Diego, CA, USA, August, pp. 635-640.

Natural England (2016) Conservation 21: Natural England's Conservation Strategy for the 21st Century. Her Majesty's Government, London, UK.

Ormsby C (2009) A Framework for Estimating the Total Cost of Buried Municipal Infrastructure Renewal Projects. MS thesis, Department of Civil Engineering and Applied Mechanics, McGill University, Montreal, QC, Canada.
Osman H and El-Diraby TE (2005) Subsurface Utility Engineering in Ontario: Challenges and Opportunities. Ontario Sewer and Watermain Construction Association, Mississauga, ON, Canada.

Pike A, Rodríguez-Pose A and Tomaney J (2017) Shifting horizons in local and regional development. Regional Studies 51(1): 46-57, https://doi.org/10.1080/00343404.2016.1158802.

Rogers CDF, Hao T, Costello SB et al. (2012) Condition assessment of the surface and buried infrastructure - a proposal for integration. Tunnelling and Underground Space Technology 28: 202-211, https:// doi.org/10.1016/j.tust.2011.10.012.

Rogers CDF, Metje N, Makana LO et al. (2017) Assessing the underworld understanding the context for engineering the next generation infrastructure. In International Symposium for Next Generation Infrastructure, 11-13 Sep 2017. ICE, London, UK, pp. 341-350.

Rogers CDF (2018) Engineering future liveable, resilient, sustainable cities using foresight. Civil Engineering, Proceedings of the Institution of Civil Engineers 271(2): 1-7, https://doi.org/10.1680/jcien.17.00031.

Sanghvi AP (1982) Economic costs of electricity supply interruptions: US and foreign experience. Energy Economics 4(3): 180-198, https://doi. org/10.1016/0140-9883(82)90017-2.

Sinha SK, Thomas HR, Wang MC and Jung YJ (2007) Subsurface Utility Engineering Manual. Pennsylvania Transportation Institute, Pennsylvania State University, Pennsylvania, PA, USA.

Talmaki S and Kamat VR (2012) Real-time hybrid virtuality for prevention of excavation related utility strikes. Journal of Computing in Civil Engineering 28(3): 04014001, https://doi.org/10.1061/(ASCE)CP. 1943-5487.0000269.

Tighe S, Lee T, McKim R and Haas R (1999) Traffic delay cost savings associated with trenchless technology. Journal of Infrastructure Systems 5(2): 45-51, https://doi.org/10.1061/(ASCE)1076-0342(1999) $5: 2(45)$

Tsunokawa K and Hoban C (1997) Roads and the Environment: a Handbook. World Bank, Washington, DC, USA, World Bank Technical Paper No. 376.

Usag (Utility Strike Avoidance Group) (2015) 2013 Utility Strike Damages Report. Usag, London, UK.

Usag (2016) 2014 Utility Strike Damages Report. Usag, London, UK.

Wang XQ, Liu BS, Allouche EN and Liu XY (2008) A practical bid evaluation method considering social costs in urban infrastructure projects. 4th IEEE International Conference on 2008, 21 September, pp. 617-622.

Weisbrod G, Vary D and Treyz G (2003) Measuring economic costs of urban traffic congestion to business. Transportation Research Record 1839: 98-106, https://doi.org/10.3141/1839-10.

Woodroffe NJ and Ariaratnam ST (2008) Cost and risk evaluation for horizontal directional drilling versus open cut in an urban environment. Practice Periodical on Structural Design and Construction 13(2): 85-92, https://doi.org/10.1061/(ASCE)1084-0680(2008)13:2(85).

Yin RK (2013) Case Study Research: Design and Methods. Sage, Thousand Oaks, CA, USA.

\section{How can you contribute?}

To discuss this paper, please submit up to 500 words to the editor at journals@ice.org.uk. Your contribution will be forwarded to the author(s) for a reply and, if considered appropriate by the editorial board, it will be published as a discussion in a future issue of the journal. 